\title{
Addressing health workforce distribution concerns: a discrete choice experiment to develop rural retention strategies in
}

\section{Cameroon}

\author{
Paul Jacob Robyn ${ }^{1^{*}}$, Zubin Shroff ${ }^{2}$, Omer Ramses Zang ${ }^{1}$, Samuel Kingue ${ }^{3}$, Sebastien Djienouassi ${ }^{4}$, \\ Christian Kouontchou ${ }^{4}$, Gaston Sorgho ${ }^{1}$
}

\begin{abstract}
Background: Nearly every nation in the world faces shortages of health workers in remote areas. Cameroon is no exception to this. The Ministry of Public Health $(\mathrm{MoPH})$ is currently considering several rural retention strategies to motivate qualified health personnel to practice in remote rural areas.

Methods: To better calibrate these mechanisms and to develop evidence-based retention strategies that are attractive and motivating to health workers, a Discrete Choice Experiment (DCE) was conducted to examine what job attributes are most attractive and important to health workers when considering postings in remote areas. The study was carried out between July and August 2012 among 351 medical students, nursing students and health workers in Cameroon. Mixed logit models were used to analyze the data.

Results: Among medical and nursing students a rural retention bonus of $75 \%$ of base salary $(\mathrm{aOR}=8.27,95 \% \mathrm{CI}$ : 5.28-12.96, $P<0.001)$ and improved health facility infrastructure ( $\mathrm{aOR}=3.54,95 \% \mathrm{CI}: 2.73-4.58)$ respectively were the attributes with the largest effect sizes. Among medical doctors and nurse aides, a rural retention bonus of $75 \%$ of base salary was the attribute with the largest effect size (medical doctors aOR=5.60, 95\% CI: 4.12-7.61, $P<0.001$; nurse aides $\mathrm{aOR}=4.29,95 \% \mathrm{CI}: 3.11-5.93, P<0.001)$. On the other hand, improved health facility infrastructure $(\mathrm{aOR}=3.56,95 \% \mathrm{CI}: 2.75-4.60, P<0.001)$, was the attribute with the largest effect size among the state registered nurses surveyed. Willingness-to-Pay (WTP) estimates were generated for each health worker cadre for all the attributes. Preference impact measurements were also estimated to identify combination of incentives that health workers would find most attractive.

Conclusion: Based on these findings, the study recommends the introduction of a system of substantial monetary bonuses for rural service along with ensuring adequate and functional equipment and uninterrupted supplies. By focusing on the analysis of locally relevant, actionable incentives, generated through the involvement of policymakers at the design stage, this study provides an example of research directly linked to policy action to address a vitally important issue in global health.

Keywords: Cameroon, Human Resources For Health, Discrete Choice Experiment (DCE), Rural Retention Strategies

Copyright: (C) 2015 by Kerman University of Medical Sciences

Citation: Robyn PJ, Shroff Z, Zang OR, Kingue S, Djienouassi S, Kouontchou C, et al. Addressing health workforce distribution concerns: a discrete choice experiment to develop rural retention strategies in Cameroon. Int J Health Policy Manag 2015; 4: 169-180. doi: 10.15171/ijhpm.2015.27
\end{abstract}

Article History:

Received: 17 May 2014 Accepted: 6 February 2015 ePublished: 11 February 2015

\section{Key Messages}

Implications for policy makers

- $\quad$ Based on a Discrete Choice Experiment (DCE) analyzed using mixed logit and Willingness-to-Pay (WTP) analysis, we recommend substantial monetary bonuses for rural service along with ensuring supplies and equipment for at least a basic package of health services to motivate health workers

- Classification of posts based on remoteness and tying level of bonuses to this may be necessary to attract health workers to the most rural areas

- Offering specialist training and housing, as proposed by the Ministry of Public Health (MoPH) were less popular incentives across health worker cadres examined

- Focusing on actionable incentives and conducting locally relevant research are vital if findings are to influence policy-making

\section{Implications for public}

Attracting and retaining qualified health workers in rural areas is a formidable challenge in most developing countries and Cameroon is no exception to this. The lack of adequate health workers in rural areas is associated with poorer health outcomes. Our research sought to examine the strategies proposed by the Cameroonian Ministry of Public Health (MoPH) that are popular in attracting health workers to rural Cameroon. The implementation of our recommendations that call for substantial monetary incentives for rural service, and ensuring availability of supplies for a basic set of services has the potential to attract a significant number of health workers to work in rural Cameroon, and mitigate the human resource crisis in the country. This in turn, may help reduce inequalities in health outcomes that are currently observed across different regions of Cameroon. 


\section{Background}

Nearly every nation in the world faces shortages of health workers in rural areas. Ensuring professionally trained, motivated health professionals are present to provide essential health services in even the most challenging areas is an essential step in the path towards universal health coverage (1-3). Crossnational evidence shows that staffing levels are closely linked with service delivery coverage and health outcomes $(4,5)$. Within countries, areas with low densities of health workers are also often areas with the worst health outcomes. For example, the states in north central India with the lowest densities of health workers have the highest rates of infant mortality in the country (6). Though many other factors may be associated with poorer health in rural areas, the availability of adequate human resources for health appears to be an important contributor (7). Policy-makers need better evidence to inform context-specific rural retention policies. Interventions to alleviate health worker shortages in medically underserved areas include initiatives such as: i) selective recruitment of individuals into healthcare education who are most likely to work in remote areas, ii) training specifically for serving in remote or challenging geographic zones, iii) improvements in working or living conditions in underserved areas, iv) compulsion, or v) incentives (8). The available evidence shows that wage bonuses, non-financial incentives, regulatory policies such as bonding, and preferential selection of students from rural areas into training programs can work to strengthen retention efforts (9). But there is no 'magic bullet' policy and there are just as many examples of failures as success. Since health worker motivation and job satisfaction are critical to their retention and performance $(7,9,10)$, the development of appropriate strategies first requires an understanding of the factors which influence decisions to accept and/or stay in a remote post, and which strategies improve attraction and retention are therefore likely to be successful (9). Due to the complex interaction of factors impacting attraction and retention, there is a strong argument to be made for bundles of interventions which include attention to living environments, working conditions and environments, and career/professional development opportunities.

Health worker preferences for human resource policy interventions vary significantly across countries. In Kenya and South Africa, better educational opportunities or rural allowances were identified to be most effective in increasing the uptake of rural posts, while in Thailand better health insurance coverage was identified as having the most effect on rural health worker retention (11). Moreover, there is a substantial body of literature on why health workers choose not to locate in rural areas (including reasons such as low pay and poor promotion opportunities), what type of incentives they value most in a job, and how this varies by type of individual $(9,12)$. But these types of studies do not provide respondents real lifelike job scenarios that allow for understanding the importance of various employment attributes of rural jobs that influence health worker decision-making behavior.

In this study, we investigate health worker preferences for a range of incentive strategies for retaining qualified health workers in remote areas of Cameroon. We use a Discrete Choice Experiment (DCE) to examine health worker retention strategy attributes that influence health workers' stated preferences for employment opportunities in remote areas. To our knowledge, this is the first study to address health worker preferences for rural retention methods in Cameroon. It provides policymakers locally relevant, actionable information on what health workers in the country desire for health service delivery in rural areas of the country. By involving policy-makers from the design stage, we link research to policy development and action.

\section{Cameroon context}

With about 11 qualified health workers per 10,000 population, Cameroon has well below the estimated need of 22.3 qualified personnel per 10,000 population according to minimum criteria established by the World Health Organization (WHO) (13). Human resource management in Cameroon is highly centralized and lacks transparency (14). Centralized planning does not allow for adequate flexibility in responding to these needs. The majority of physicians in the country are based in urban areas and more than half of Cameroon's health workforce is employed in three administrative regions: the Center, Littoral and West, which are home to the three largest cities in the country (Yaoundé, Douala, Bafoussam). On the other hand, the Far North region, which is home to $18 \%$ of the national population, employs only $8 \%$ of the country's physicians. Similarly, $55 \%$ of public sector nurses are concentrated in the Center, Littoral, and West regions, which together represent only $42 \%$ of the population. The majority of health professionals in rural areas are nurse aids, the classification of professional health workers in Cameroon with the lowest level of technical training (two years) (13). These characteristics are particularly true in the three northern regions of Cameroon (Far North, North and Adamaoua), which are home to the poorest health outcomes in the country.

One of the major challenges in the Cameroonian health system is the inequity in access to, and use of, health services between urban and rural areas and across administrative regions. Almost every category of health indicator is worse for those who live in remote areas and regions (defined as those located more than $80 \mathrm{~km}$ from the first referral hospital), and the gap has been increasing over the past decade (15-17). For example in the Northern region of Cameroon, in 2011 only $21.8 \%$ of births were attended by skilled personnel, compared to $93 \%$ in Littoral region and $91.6 \%$ in the West. Between 2004 and 2011 , coverage of assisted deliveries actually decreased in the Far North region, from $26.6 \%$ to $25.1 \%(15,16)$. At the national level, the maternal mortality ratio increased from 669 deaths per 100,000 live births in 2004 to 782 deaths in $2011(15,16)$, slightly higher than countries such as Liberia and Sudan even if lower than neighboring countries such as Central African Republic and Chad (Figures 1 and 2).

Recognizing the skewed distribution of the health workforce as a key impediment towards the achievement of universal health coverage, the Ministry of Public Health $(\mathrm{MoPH})$ is currently developing several rural retention strategies to motivate qualified health personnel to practice in rural areas, including both financial and non-financial incentives. These include: i) rural retention bonuses, ii) preferential admission for additional training opportunities for health workers completing service in remote areas, and iii) guaranteed reassignment to urban areas after completion of rotational assignments in remote areas. To better calibrate these mechanisms and develop evidence-based retention strategies that are attractive and motivating to health 


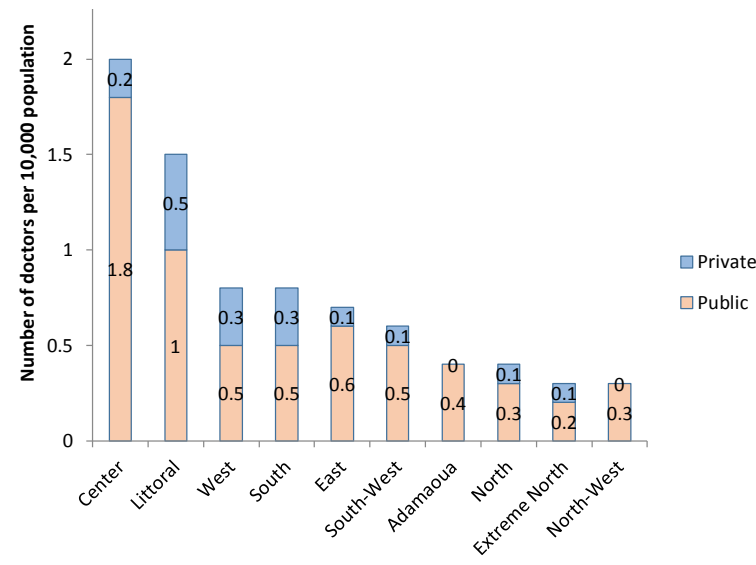

Figure 1. Health worker density by region and sector, doctors. Source: Health workforce census, 2011, DHR/MS

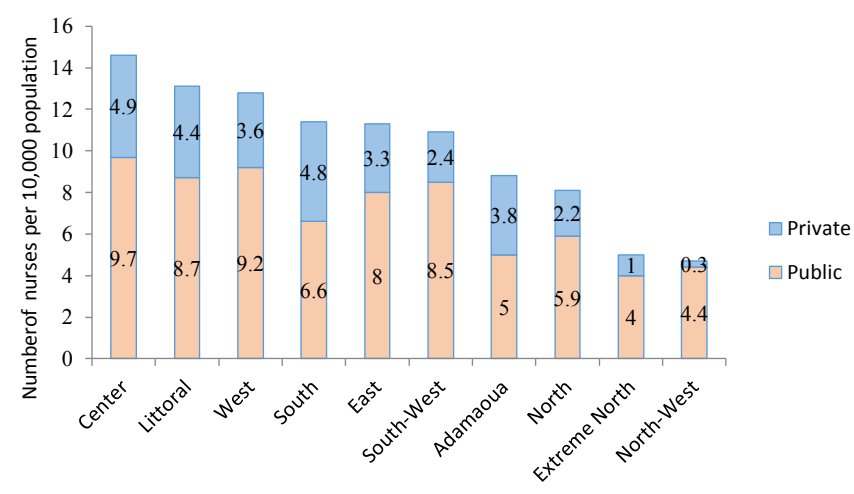

Figure 2. Health worker density by region and sector, nurses. Source: Health workforce census, 2011, DHR/MS

workers, the World Bank, in collaboration with the Direction of Human Resources (DHRs) at the MoPH and Institute for Survey and Statistical Analysis (ISSA), conducted a DCE to examine health worker preferences for rural job postings.

\section{Methods}

The DCE is a technique that aims to elicit stated preferences of individuals. Random Utility Theory provides the theoretical foundation for DCEs (18). Utility is unobservable and must be inferred from the individual's job choices. A utility maximizing individual will choose the job that he or she does, if and only if, the chosen job provides a higher level of utility than the alternative job (18). The probability that individual $I$ will choose job j over job $k$ can be written as:

$\mathrm{Pij}=\mathrm{P}[\mathrm{Uij}>\mathrm{Uik}]$

$\mathrm{Pij}=\mathrm{P}[\mathrm{Vij}+\varepsilon \mathrm{ij}>\mathrm{Vik}+\varepsilon \mathrm{ik}]$

$P i j=P[V i j-V i k>\varepsilon i k-\varepsilon i j] i \neq j$

By making assumptions about the distribution of the random component, choice models can be derived that can be analyzed using standard econometric techniques $(7,18)$. Through asking respondents to choose between hypothetical alternatives, DCEs help understand an individual's valuation of different attributes of a product, policy or program (19). One of the most common applications of DCEs is to inform policy related to retention of health workers in remote or hardship zones. Studies with this intention include those by Kolstad (20) in Tanzania, Mangham and Hanson (21) in Malawi, Kruk et al. (22) in Ghana, a multi-country study by Blaauw et al. (11), and by Vujicic et al. (7) in Vietnam. More recent papers include those by Rockers et al. (23) looking at job preferences of trainee health professionals in Uganda, by Rao et al. (6) examining job preferences of doctors, nurses, medical students and nursing students in two states of India and by Rockers et al. (24) examining preferences of nursing students and practicing nurses in the Lao PDR.

A systematic review by Mandeville et al. (25) of DCEs to inform health work policy was recently conducted and identified the importance across similar studies of rural allowances/bonuses and opportunities for further training for the uptake of rural posts, while time commitments were found to be generally unpopular. Araújo and Maeda (26) note that there are several limitations to conducting DCEs for human resources for health policy: i) there remains limited evidence on the reliability of DCEs when predicting labor force decisions; ii) the number of job attributes and levels within each attribute should remain limited (six to seven) to avoid cognitive burden to respondents; and iii) DCE survey respondents must trade off between attributes and apply compensatory decision rules. If respondents do not understand the choice exercise or make choices based on a single attribute, results may be invalid. Findings in this study are based on a survey carried out between July and August 2012 among medical students, nursing students and health workers in Cameroon. The study sample included seventh year medical students from the Faculty of Medicine of the University of Yaoundé I, third year State-Registered Nurse nursing students from one public and one private nursing school in Yaoundé, and public sector health professionals such as generalist doctors from Yaoundé, North and East regions, and state-registered nurses and nurse aides from the North and East regions. The North and East regions were chosen by the Director of Human Resources at the $\mathrm{MoPH}$ due to their critical shortages in retaining qualified health workers. The districts were selected in each region were chosen by the Regional Health Delegation for that region, based on their accessibility and presence of qualified staff at the facility. While random sampling was not conducted, an initial discussion was held with each Regional Health Delegation regarding the selection process of facilities to ensure that the sites selected were representative of the rural and isolated sites targeted by the proposed rural retention strategies. Administrative authorization for the study was provided by the MoPH.

As a first step, we carried out four focus group discussions to inform the study design. The 63 respondents included medical doctors, nurses, medical students and nursing students. These were held at the end of June 2012 at four locations in Yaoundé, namely the District Hospital Biyem Assi (12 participants), a public nursing school (14 participants), a faith-based nursing school (13 participants) and the Faculty of Medicine at the University of Yaoundé (13 participants). Respondents were asked to describe what they perceived as a 'good' and a 'bad' job, both in terms of characteristics of the job and their expectations on each of the characteristics. Respondents were also specifically asked about working in rural areas and the incentives, both monetary and non-monetary that they would need to receive in return for working in a rural area. At the end of the discussions, respondents were presented and asked to rank seven attributes that were generated based on discussions with the $\mathrm{MoPH}$ and a review of the literature from other developing countries, they were also asked to provide 
other attributes that they thought important and that were not in our list (Table 1). The final attributes were decided on the basis of the focus group discussions as well as discussions with senior officials in the Ministry of Health (Table 2). Baseline and baseline-plus-bonus salaries for students and health workers were estimated using official documents from the DHRs at the $\mathrm{MoPH}$. Using these attributes, hypothetical job scenarios were generated. Respondents were asked to choose between a series of these scenarios each consisting of different attribute-level combinations.

Choice sets were generated using the Ngene software (27) which created an orthogonal optimal in the differences design with no overlap of attributes (respondents were forced to trade off attributes) and attribute level balance (each attribute level occurred an equal number of times across the whole questionnaire), following the design principles and construction techniques put forward in Street et al. (28). This design ensures that respondents are compelled to trade across attributes throughout the experiment, while the orthogonality enables estimation of the influence of each of the attributes on the choice. The disadvantages of this design are that forcing attributes to be different across alternatives may enable a particular dominant attribute to drive an individual's choices throughout the experiment and that this design may only be used in unlabeled DCEs (27).

The final orthogonal optimal in the differences design generated by the Ngene software had 24 choice sets with a D-efficiency of over $97 \%$. While health applications generally have used smaller numbers of choice sets; the use of 32 choice sets per respondent has been identified in the broader literature, with as many as 28 used in health applications (18). Each choice set posed two questions to the respondent. First, the respondents were asked to choose between the two rural jobs. The second question varied according to the type of respondent. In order to provide an opt-out option, students were asked if they would actually take up the job that they chose if it were offered to them and health workers were asked if they would give up their current job for the job they selected in the questionnaire. For health workers, the last question of the survey asked them to characterize their current job in terms of the six attributes used to generate the choice sets (Figure 3).

Development of the attribute levels took into account responses from the qualitative study as well as the political and financial feasibility of hardship bonuses while deciding on the four levels of the salary attribute to be offered to the respondents. To take into account different salaries according to seniority, we described the salary attribute in terms of the respondents' current salary plus a percentage increase of varying levels

Table 1. Ranking job posting attributes, focus group discussion participants

\begin{tabular}{|c|c|c|c|c|c|c|c|c|}
\hline Attribute & $\begin{array}{c}7 \text { (Most } \\
\text { important) }\end{array}$ & 6 & 5 & 4 & 3 & 2 & $\begin{array}{c}1 \text { (Least } \\
\text { important) }\end{array}$ & Total score* \\
\hline Salary & 30 & 16 & 5 & 6 & 4 & 1 & 1 & 370 \\
\hline Availability of housing for staff at health facility & 5 & 19 & 15 & 6 & 6 & 6 & 6 & 284 \\
\hline Accessibility and connectivity of the workplace & 11 & 10 & 13 & 8 & 5 & 8 & 8 & 273 \\
\hline Availability of drugs and equipment at the facility & 4 & 11 & 9 & 16 & 14 & 8 & 1 & 262 \\
\hline Opportunities for career development & 10 & 5 & 8 & 5 & 10 & 21 & 4 & 236 \\
\hline Sufficient personnel at health facility for workload & 2 & 1 & 10 & 18 & 15 & 10 & 7 & 214 \\
\hline $\begin{array}{l}\text { Possibility of job assignment in urban areas after a } \\
\text { fixed period }\end{array}$ & 1 & 1 & 3 & 4 & 9 & 9 & 36 & 125 \\
\hline Total respondents & 63 & 63 & 63 & 63 & 63 & 63 & 63 & \\
\hline
\end{tabular}

*Total score $=$ Scores were calculated by multiplying the number of respondents by the score per rank order (highest $=7$ points, lowest $=1$ point) and adding the total points per attribute

Table 2. Attributes and levels used in questionnaire design

\begin{tabular}{|c|c|c|}
\hline Attribute & Level & Description \\
\hline \multirow{2}{*}{$\begin{array}{l}\text { Accessibility and } \\
\text { connectivity of the } \\
\text { workplace to the city }\end{array}$} & 1 & $\begin{array}{l}\text { Your facility is located in a village with poor connectivity - reliable transportation to the health district capital twice a week } \\
\text { or less }\end{array}$ \\
\hline & 2 & Your facility is located in a village with good connectivity - reliable transportation to the health district capital every day \\
\hline \multirow{2}{*}{$\begin{array}{l}\text { Health facility } \\
\text { infrastructure }\end{array}$} & 1 & $\begin{array}{l}\text { Lack of equipment, drugs and frequent shortages of inputs for most services that you are supposed to provide at the primary } \\
\text { healthcare level (delivery, vaccination, prenatal consultation and general consultation) }\end{array}$ \\
\hline & 2 & $\begin{array}{l}\text { Adequate equipment, drugs and rare shortages of inputs for most services that you are supposed to provide at the primary } \\
\text { healthcare level (delivery, vaccination, prenatal consultation and general consultation) }\end{array}$ \\
\hline \multirow[b]{2}{*}{ Lodging } & 1 & No accommodation provided (only an additional allowance for housing as currently given to you) \\
\hline & 2 & $\begin{array}{l}\text { A good quality house is made available in a secure location with access to drinking water (in addition to housing benefit } \\
\text { being provided) }\end{array}$ \\
\hline \multirow{2}{*}{ Career development } & 1 & $\begin{array}{l}\text { No preferential admission for health workers in rural areas for ongoing training available (placement exam with equal } \\
\text { chances) }\end{array}$ \\
\hline & 2 & $\begin{array}{l}\text { Establishment of preferential admission for ongoing training available to your level via a quota of } 20 \% \text { of seats reserved for } \\
\text { those who worked for at least } 4 \text { years in rural areas }\end{array}$ \\
\hline \multirow{4}{*}{$\begin{array}{l}\text { Salary (inc. all } \\
\text { bonuses) }\end{array}$} & 1 & Your base salary at its current level \\
\hline & 2 & Your base salary at its current level $+25 \%$ rural retention bonus \\
\hline & 3 & Your base salary at its current level $+50 \%$ rural retention bonus \\
\hline & 4 & Your base salary at its current level $+75 \%$ rural retention bonus \\
\hline \multirow{2}{*}{$\begin{array}{l}\text { Job assignment in an } \\
\text { urban area }\end{array}$} & 1 & Uncertain \\
\hline & 2 & Automatic after 3 years \\
\hline
\end{tabular}


for accepting to work in a rural hardship post. However, to provide a reference point for students, information on entry level salaries for doctors and state-registered nurses (including all benefits) was obtained from DHR and was used to generate the attribute levels. The highest level on the salary attributed corresponded to $75 \%$ of the respondent's current salary (including all benefits) or, in the case of students, entry level salaries for their cadre (including all benefits).

The questionnaire included one choice set, in addition to the 24 generated by the software, where all attributes in one of the two job options were dominant and would be expected to be chosen by a rational respondent. This choice set was presented as choice set 15, and served as a test, enabling detection of respondents who were likely to have been randomly marking the questionnaire or did not understand how to complete the questionnaire. The questionnaire also included questions on background demographic characteristics of respondents, including age, gender, rural upbringing, marital status, education and work place characteristics (for currently active health workers).

Mixed logit regression was used for the statistical analysis. These models allow for heterogeneity in preferences and also enable one to model repeated choices made by the same individual. They overcome a number of the restrictions of, and are therefore an improvement over models such as the conditional logit (22). All statistical analysis was done using Stata 11. For ease of understanding, all mixed logit coefficients were exponentiated and presented as Odds Ratios (OR).

Based on mixed logit estimates, Willingness-to-Pay (WTP) estimates for each of the attributes were generated (29). The WTP measure conveys in monetary terms, respondents' preferences for rural job attributes or a combination of attributes or incentive mechanisms, relative to a standard rural job posting or reference level void of incentives (status quo). In order to obtain WTP estimates, each attribute coefficient of the mixed logit model was divided by the salary coefficient of the mixed logit model (29). Baseline and baseline plus bonus salaries for students and health workers were estimated using official documents from the DHRs at the MoPH. All WTP estimates use salary levels for civil servants and not contracted health personnel.

Preference impact measures were then estimated for different packages (27). This measure estimates the percentage of each cadre that would prefer that package, compared to the status quo for rural postings. In other words, the preference impact measure examines how combinations of different levels of attributes alters the likelihood that health workers and students would select a given job (29). These were calculated by taking the attribute coefficients from the mixed logit model results and using the following equation in Excel (29):

$$
\frac{\left(\frac{e^{(\text {proposed job preference value })}}{e^{(\text {standard job preference value })}}\right)}{\left(1+\left(\frac{e^{(\text {proposed job preference value })}}{e^{(\text {standard job preference value })}}\right)\right)}
$$

The job preference value is the sum of the mixed logit coefficients for all attributes that are included in the given job description, whether it be the proposed incentive package or status quo standard scenario. For this study, the status quo scenario includes the baseline level for each job attribute, as no incentives are currently being offered within the framework adopted for this DCE and the descriptive characteristics of the baseline scenario are largely representative of workplace settings for health workers in rural areas of Cameroon.

Results

The study included a total of 351 respondents (Table 3). Medical doctors in Yaoundé were found to be difficult to have participate in the survey, leading to a smaller than expected sample from this group. Data collection in the other two regions proceeded smoothly, with the survey team using the launch of the Performance-Based Financing (PBF) project in the East Region to take advantage of the large number of health workers that were participating in the regional launching

\begin{tabular}{|c|c|}
\hline & Job 1 \\
\hline $\begin{array}{l}\text { Accessibility and } \\
\text { connectivity of the } \\
\text { workplace to the } \\
\text { city }\end{array}$ & $\begin{array}{l}\text { Your facility is located in a village with poor } \\
\text { connectivity - reliable transportation to the } \\
\text { health district capital twice a week or less }\end{array}$ \\
\hline $\begin{array}{l}\text { Health facility } \\
\text { infrastructure }\end{array}$ & $\begin{array}{l}\text { Lack of equipment, drugs and frequent shortage } \\
\text { of inputs for most services that you are supposed } \\
\text { to provide at the primary healthcare level } \\
\text { (delivery, vaccination, prenatal consultation and } \\
\text { general consultation) }\end{array}$ \\
\hline Lodging & $\begin{array}{l}\text { A good quality house is made available in a } \\
\text { secure location with access to drinking water (in } \\
\text { addition to housing benefit being provided) }\end{array}$ \\
\hline $\begin{array}{l}\text { Career } \\
\text { development }\end{array}$ & $\begin{array}{l}\text { No preferential admission for health workers in } \\
\text { rural areas for ongoing training available } \\
\text { (placement exam with equal chances) }\end{array}$ \\
\hline $\begin{array}{l}\text { Salary (including all } \\
\text { bonuses) }\end{array}$ & $\begin{array}{l}\text { Your base salary at its current level }+75 \% \text { rural } \\
\text { retention bonus }\end{array}$ \\
\hline $\begin{array}{l}\text { Job assignment in } \\
\text { an urban area }\end{array}$ & Uncertain \\
\hline
\end{tabular}

Example combination of choice: which of these jobs would you prefer?

Which of these jobs would you prefer?

Will you be ready to accept the job you have chosen in place of your current job

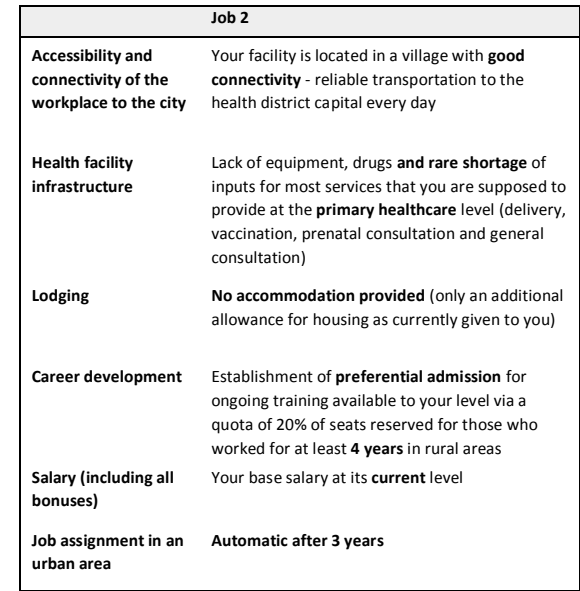

Job 1

Yes

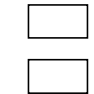

Job 2

No

Figure 3: Example choice set: health workers 
workshop. Health workers from all fourteen health districts in the region were present at the workshop and participated in the DCE. In the North, the districts of Garoua II, Pitoa and Guider were included in the survey, where 10 primary care facilities and two district hospitals health facilities were visited by the survey team. Descriptive statistics of the sample population are provided in Table 4 . Two students, both nursing students, and eight health workers, chose the inferior job option for the test of dominance. This low rate of failure of the dominance test ruled out large scale cognitive fatigue on the part of the respondents that may be a potential problem in a study with 24 choice sets.

Table 5 displays the number of respondents for each choice set who picked one of the two hypothetical jobs offered to them. For students, this figure represents the number of students who stated that they would take up the job that they chose if it were offered to them. For health workers this number represents those who would give up their current job to pick the job they selected in the questionnaire.

Main effects regression analysis was done with and without individuals who failed the dominance test as a test of sensitivity. Findings were similar in significance and effect sign and these individuals were kept in the sample for subsequent analysis, in line with suggested best practice from the literature (18).

\section{Students}

Table 6 shows the results of the main effects mixed logit model, displaying adjusted odds ratios for each of the attribute levels. All attribute levels were significantly different from zero. Among the sample of 45 medical students, a rural retention bonus of $75 \%$ of base salary was the attribute with the largest effect size $(\mathrm{aOR}=8.27, \mathrm{CI}: 5.28-12.96, P<0.001)$. This was followed by the attribute good health facility infrastructure, defined in terms of adequacy of equipment, drugs and inputs for the provision of services at the primary care level $(\mathrm{aOR}=5.94$, CI: 3.73-9.47, $P<0.001)$. For the nursing students in the sample $(n=95)$, the regression coefficients for both good infrastructure $(\mathrm{aOR}=3.54, \mathrm{CI}: 2.73-4.58, P<0.001)$ and guaranteed transfer $(\mathrm{aOR}=2.81, \mathrm{CI}: 2.22-3.56, P<0.001)$ were of a larger magnitude than that associated with a $75 \%$ rural retention bonus $(\mathrm{aOR}=1.80, \mathrm{CI}: 1.42-2.29, P<0.001)$.

Interaction terms for gender and rural upbringing were each tested in a single model for each cadre. Among medical students, female gender had a positive effect on selecting a job with a guaranteed transfer $(\mathrm{aOR}=5.52, \mathrm{CI}: 2.54-12.03, P<0.001)$. Respondents brought up in a rural area were significantly more likely to pick a job with better health facility infrastructure than those brought up in urban areas $(\mathrm{aOR}=3.21$, CI: 1.666.20, $P<0.001)$. They were also significantly more likely to select a job with a guaranteed transfer $(\mathrm{aOR}=2.80$, CI: 1.50 5.22, $P<0.001)$. Among nursing students, those brought up in a rural area were significantly more likely to take up a job with a guaranteed transfer $(\mathrm{aOR}=1.68, \mathrm{CI}: 1.00-2.81, P=0.049)$. All remaining interaction terms were not statistically significant.

\section{Health workers}

Medical doctors $(n=77)$ had stated preferences similar to medical students (Table 7). A 75\% rural retention bonus had the biggest effect size $(\mathrm{aOR}=5.60, \mathrm{CI}: 4.12-7.61, P<0.001)$, followed by good health facility infrastructure $(\mathrm{aOR}=3.76$, CI: $2.88-4.90, P<0.001)$. As with the students, accessibility of health facility to the district capital $(\mathrm{aOR}=1.59$, CI: $1.30-1.95$, $P<0.001)$ and a $25 \%$ rural retention bonus $(\mathrm{aOR}=1.91, \mathrm{CI}$ : $1.50-2.43, P<0.001)$ were the attributes that had the smallest effect sizes.

In common with nursing students, the salary attribute was of a smaller magnitude than facility infrastructure for the group of practicing state-registered nurses $(n=74)$. The attribute,

Table 3. Sample for quantitative phase

\begin{tabular}{|c|c|c|c|c|}
\hline & Medical students & Nursing students & Generalist doctors & State-registered nurses/nursing aides \\
\hline Centre region & $45(100)^{a}$ & $96(100)$ & $53(100)$ & $0(0)$ \\
\hline North region (Garoua II, Pitoa, Guider) & $0(0)$ & $0(0)$ & $2(0)$ & $63(50)$ \\
\hline East region (all 14 districts) & $0(0)$ & $0(0)$ & $22(0)$ & $73(50)$ \\
\hline Total & $45(100)$ & $96(100)$ & $77(100)$ & $136(100)$ \\
\hline
\end{tabular}

Target sample is given in parenthesis

Table 4. Descriptive statistics

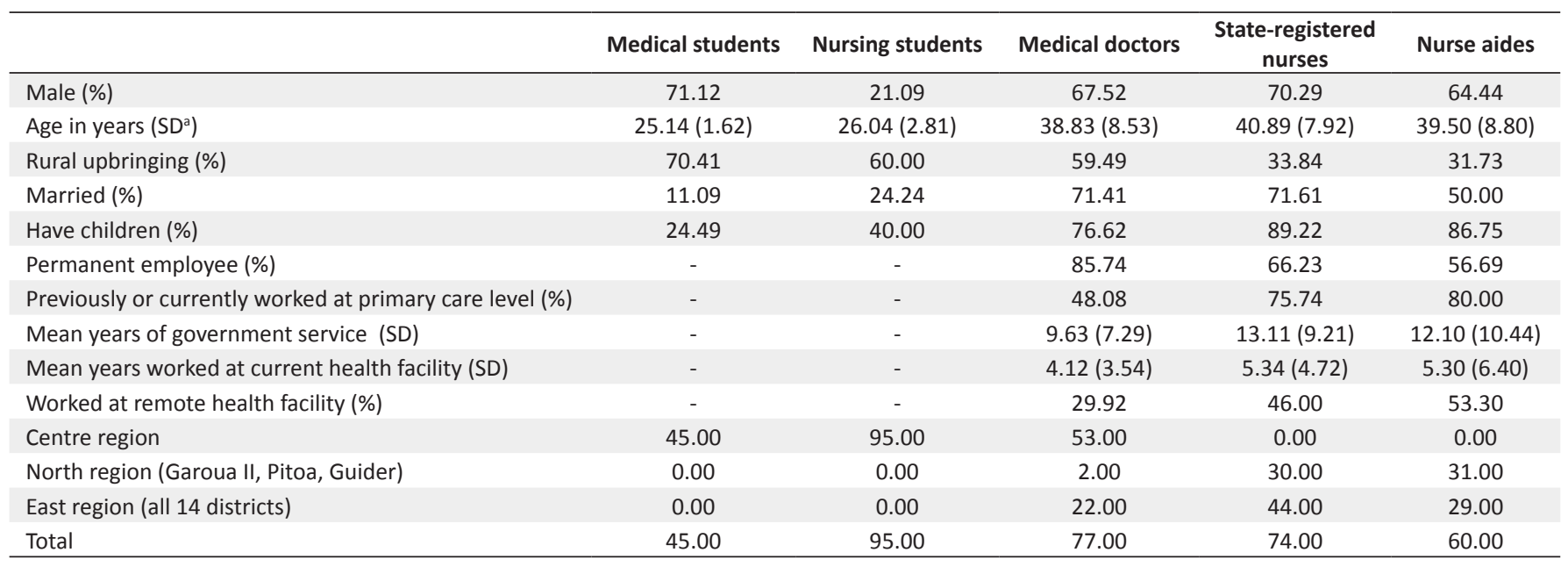

${ }^{1} \mathrm{SD}=$ Standard Deviation 
good health facility infrastructure had the largest effect size $(\mathrm{aOR}=3.56$, CI: $2.75-4.60, P<0.001)$, followed by the highest salary attribute $(\mathrm{aOR}=3.13, \mathrm{CI}: 2.43-4.03, P<0.001)$. For nurse aides $(n=60)$, a75\% rural retention bonus $(\mathrm{aOR}=4.29$, CI: 3.11 5.93, $P<0.001)$ had the largest effect size, while a guaranteed transfer after service in remote areas had no effect on job choice $(\mathrm{aOR}=1.14, \mathrm{CI}: 0.97-1.33, P=0.107$; Table 7$)$.

Table 5. Number of respondents who would pick one of the two hypothetical jobs offered in each choice set

\begin{tabular}{|c|c|c|}
\hline Choice set & Students $(n=140)$ & Health workers $(n=211)$ \\
\hline 1 & 101 & 128 \\
\hline 2 & 124 & 152 \\
\hline 3 & 101 & 120 \\
\hline 4 & 127 & 163 \\
\hline 5 & 93 & 124 \\
\hline 6 & 90 & 125 \\
\hline 7 & 116 & 148 \\
\hline 8 & 102 & 132 \\
\hline 9 & 85 & 124 \\
\hline 10 & 100 & 135 \\
\hline 11 & 97 & 126 \\
\hline 12 & 91 & 124 \\
\hline 13 & 87 & 130 \\
\hline 14 & 86 & 124 \\
\hline 15 & 131 & 168 \\
\hline 16 & 82 & 114 \\
\hline 17 & 105 & 142 \\
\hline 18 & 102 & 134 \\
\hline 19 & 91 & 133 \\
\hline 20 & 96 & 145 \\
\hline 21 & 91 & 138 \\
\hline 22 & 79 & 112 \\
\hline 23 & 108 & 149 \\
\hline 24 & 95 & 126 \\
\hline 25 & 97 & 137 \\
\hline
\end{tabular}

Interaction terms for gender, rural upbringing and contractbased employment status (versus civil servant status) were each tested in a single model for each cadre of health workers. Among medical doctors, rural upbringing was positively and significantly associated with choosing a job in a health facility that was accessible to the district capital $(\mathrm{aOR}=2.14, \mathrm{CI}: 1.21$ 3.81, $P=0.009)$, that had good infrastructure $(\mathrm{aOR}=1.76, \mathrm{CI}$ : $1.31-3.01, P=0.040)$, that provided a $25 \%$ rural retention bonus $(\mathrm{aOR}=1.83$, CI: $1.09-3.08, P=0.022)$, the provided a $75 \%$ rural retention bonus $(\mathrm{aOR}=2.16, \mathrm{CI}: 1.13-4.17, P=0.021)$ and that guaranteed transfer after service in a rural area $(\mathrm{aOR}=1.67, \mathrm{CI}$ : 1.05-2.64, $P=0.029$ ). Female doctors were more likely to choose a job with good health facility infrastructure $(\mathrm{aOR}=3.71, \mathrm{CI}$ : 2.00-6.86, $P<0.001)$ and a job with a $25 \%$ rural retention bonus $(\mathrm{aOR}=2.32$, CI: $1.21-4.43, P=0.011)$. Doctors with contractual appointments were more likely to choose a job with good housing $(\mathrm{aOR}=2.34$, $\mathrm{CI}: 1.21-4.56, P=0.011)$.

Among state registered nurses, rural upbringing was positively and significantly associated with choosing a job that would provide preferential admission for in-service training (aOR=1.72, CI: 1.06-2.78, $P=0.028$ ). Female gender was associated with choosing a job with good health facility infrastructure $(\mathrm{aOR}=3.71, \mathrm{CI}: 2.00-6.86, \quad P<0.001)$ and with a job with a $25 \%$ rural retention bonus $(\mathrm{aOR}=2.32$, CI: $1.21-4.43, P=0.011)$. State registered nurses with contractual appointments were significantly more likely to choose a job with good health facility infrastructure, compared to those having civil servant status ( $\mathrm{aOR}=2.35$, $\mathrm{CI}: 1.38-3.99, P=0.002$ ), they were also more likely to choose a job with good housing $(\mathrm{aOR}=1.67, \mathrm{CI}: 1.14-2.45, P=0.009)$ and a job that was in a health facility that was easily accessible to the district headquarter $(\mathrm{aOR}=1.59, \mathrm{CI}$ : 1.04-2.41, $P=0.003)$. Nurse aides with contractual appointments were significantly more likely to choose a job with good health facility infrastructure when compared to those having civil servant status ( $\mathrm{aOR}=1.91, \mathrm{CI}$ : $1.14-1.17, P=0.014)$. However, they were significantly less likely

Table 6. Mixed logit model main effects, students

\begin{tabular}{|c|c|c|c|c|}
\hline Attribute (Mean) & Medical students aOR $(95 \% \mathrm{Cl})$ & $P$-value & Nursing students aOR $95 \% \mathrm{Cl}$ ) & $P$-value \\
\hline Accessibility and connectivity & $1.38(1.06-1.79)$ & 0.016 & $1.52(1.28-1.80)$ & $<0.001$ \\
\hline Health facility infrastructure & $5.94(3.73-9.47)$ & $<0.001$ & $3.54(2.83-4.58)$ & $<0.001$ \\
\hline Lodging & $2.00(1.58-2.55)$ & $<0.001$ & $1.68(1.44-1.95)$ & $<0.001$ \\
\hline Career development & $1.81(1.39-2.37)$ & $<0.001$ & $1.88(1.61-2.20)$ & $<0.001$ \\
\hline $25 \%$ rural retention bonus & $1.83(1.33-2.52)$ & $<0.001$ & $1.41(1.14-1.74)$ & 0.001 \\
\hline $50 \%$ rural retention bonus & $3.37(2.26-5.02)$ & $<0.001$ & $1.81(1.41-2.31)$ & $<0.001$ \\
\hline $75 \%$ rural retention bonus & $8.27(5.28-12.96)$ & $<0.001$ & $1.80(1.42-2.29)$ & $<0.001$ \\
\hline Job assignment to an urban area & $2.86(2.13-3.84)$ & $<0.001$ & $2.81(2.22-3.56)$ & $<0.001$ \\
\hline \multicolumn{5}{|l|}{ SD } \\
\hline Accessibility and connectivity & $2.06(1.55-2.74)$ & $<0.001$ & $2.14(1.65-2.78)$ & $<0.001$ \\
\hline Health facility Infrastructure & $4.22(2.88-6.20)$ & $<0.001$ & $3.38(2.62-4.37)$ & $<0.001$ \\
\hline Lodging & $0.58(0.45-0.74)$ & $<0.001$ & $1.59(1.29-1.95)$ & $<0.001$ \\
\hline Career development & $1.73(1.29-2.30)$ & $<0.001$ & $1.89(1.53-2.32)$ & $<0.001$ \\
\hline $25 \%$ rural retention bonus & $0.90(0.59-1.38)$ & 0.626 & $1.15(0.87-1.53)$ & 0.324 \\
\hline $50 \%$ rural retention bonus & $1.06(0.69-1.64)$ & 0.797 & $0.54(0.73-1.22)$ & 0.633 \\
\hline $75 \%$ rural retention bonus & $2.48(1.61-3.82)$ & $<0.001$ & $0.47(0.37-0.60)$ & $<0.001$ \\
\hline Job assignment to an urban area & $2.67(1.84-3.87)$ & $<0.001$ & $3.78(2.98-4.80)$ & $<0.001$ \\
\hline Sample & $n=45$ & & $n=95$ & \\
\hline Observations & 2,160 & & 4,560 & \\
\hline
\end{tabular}

${ }^{1} \mathrm{aOR}=$ Adjusted Odds Ratio, 95\% Cl= 95\% Confidence Interval 
Table 7. Mixed logit model main effects, health workers

\begin{tabular}{|c|c|c|c|c|c|c|}
\hline Attribute (Mean) & $\begin{array}{c}\text { Medical Doctors aOR } \\
(95 \% \mathrm{Cl})\end{array}$ & $P$-value & $\begin{array}{c}\text { State-Registered urses } \\
\text { aOR }(95 \% \mathrm{Cl})\end{array}$ & $P$-value & $\begin{array}{c}\text { Nurse Aides aOR } \\
(95 \% \mathrm{Cl})\end{array}$ & $P$-value \\
\hline Accessibility and connectivity & 1.59 (1.30-1.95) & $<0.001$ & $1.34(1.13-1.60)$ & 0.001 & $1.33(1.13-1.57)$ & 0.001 \\
\hline Health Facility Infrastructure & $3.76(2.88-4.90)$ & $<0.001$ & $3.56(2.75-4.60)$ & $<0.001$ & $2.90(2.18-3.83)$ & $<0.001$ \\
\hline Lodging & $2.03(1.70-2.42)$ & $<0.001$ & $1.75(1.48-2.08)$ & $<0.001$ & $1.61(1.34-1.94)$ & $<0.001$ \\
\hline Career Development & $1.99(1.66-2.38)$ & $<0.001$ & $1.77(1.45-2.17)$ & $<0.001$ & $1.98(1.55-2.53)$ & $<0.001$ \\
\hline $25 \%$ Rural Retention Bonus & $1.91(1.50-2.43)$ & $<0.001$ & $1.36(1.08-1.71)$ & $<0.001$ & $1.62(1.27-2.09)$ & $<0.001$ \\
\hline $50 \%$ Rural Retention Bonus & $3.36(2.50-4.51)$ & $<0.001$ & $2.31(1.75-3.03)$ & $<0.001$ & $2.66(1.98-3.57)$ & $<0.001$ \\
\hline 75\% Rural Retention Bonus & $5.60(4.12-7.61)$ & $<0.001$ & $3.13(2.43-4.03)$ & $<0.001$ & 4.29 (3.11-5.93) & $<0.001$ \\
\hline Job Assignment to an urban area & $2.35(1.90-2.92)$ & $<0.001$ & $1.65(1.32-2.06)$ & $<0.001$ & $1.14(0.97-1.33)$ & 0.107 \\
\hline \multicolumn{7}{|l|}{ SD } \\
\hline Accessibility and connectivity & $2.27(1.78-2.89)$ & $<0.001$ & $0.53(0.42-0.66)$ & $<0.001$ & $1.39(1.12-1.73)$ & 0.003 \\
\hline Health Facility Infrastructure & $2.85(2.26-3.59)$ & $<0.001$ & $3.24(2.52-4.17)$ & $<0.001$ & $3.79(2.76-5.20)$ & $<0.001$ \\
\hline Lodging & $1.76(1.42-2.19)$ & $<0.001$ & $1.61(1.30-2.01)$ & $<0.001$ & $1.76(1.41-2.20)$ & $<0.001$ \\
\hline Career Development & $1.74(1.43-2.12)$ & $<0.001$ & $2.28(1.80-2.88)$ & $<0.001$ & $2.28(1.80-2.88)$ & $<0.001$ \\
\hline $25 \%$ Rural Retention Bonus & $0.88(0.63-1.22)$ & 0.444 & $0.94(0.67-1.30)$ & 0.690 & $0.85(0.64-1.12)$ & 0.248 \\
\hline $50 \%$ Rural Retention Bonus & $0.98(0.74-1.30)$ & 0.876 & $1.01(0.71-1.45)$ & 0.946 & $1.17(0.85-1.62)$ & 0.340 \\
\hline 75\% Rural Retention Bonus & $1.84(1.36-2.50)$ & $<0.001$ & $0.75(0.46-1.22)$ & 0.250 & $0.51(0.38-0.67)$ & $<0.001$ \\
\hline Job Assignment to an urban area & $2.80(2.12-3.70)$ & $<0.001$ & $2.31(1.82-2.92)$ & $<0.001$ & 1.35 (1.09-1.66) & 0.005 \\
\hline Sample & $n=77$ & & $n=74$ & & & $n=60$ \\
\hline Observations & 3,696 & & 3,552 & & & 2,880 \\
\hline
\end{tabular}

${ }^{1} \mathrm{aOR}=$ Adjusted Odds Ratio, 95\% Cl= 95\% Confidence Interval

to choose a job with a $75 \%$ rural retention bonus, compared to health workers having civil servant status ( $\mathrm{aOR}=0.45$, CI: 0.23 $0.78, P=0.018)$.

\section{Willingness-to-Pay (WTP)}

The WTP values in Table 8 show that both medical students and nursing students value adequatehealth facility infrastructure the most $(86,529$ FCFA forgone salary for medical students and 129,000 FCFA forgone salary for nursing students), followed by reassignment to an urban area after completion of 3 years in a rural post $(58,118$ FCFA forgone salary for medical students and 125,750 FCFA forgone salary for nursing students). It should be noted that the reason forgone salaries for incentive mechanisms are lower for medical students than nursing students is that medical students valued monetary incentives in the form of rural retention bonuses more than nursing students. This is most clearly identified in the mixed logit model estimates, where the adjusted odds ratio for a $75 \%$ rural retention bonus is over four times as large for medical students compared to nursing students $(\mathrm{aOR}=8.27$ vs. $\mathrm{aOR}=1.80)$.

The WTP values in Table 9 show that all health worker cadres values health facility infrastructure as the most important job attribute for rural job postings, medical doctors valued reassignment to urban areas more than twice as high as nurses and more than fifteen times as high as nurse aides. This supports the idea that medical doctors value urban posts, where most secondary and tertiary hospitals are based, much higher than lower level cadres whose clinical skills are more oriented towards primary care services which are often the only type of care provided in rural remote areas.

Tables 10 and 11 demonstrate predicted preference impact (percentage) of retention strategy packages for medical students. From these we can infer the following: a) that even adding single incentives leads respondents to greatly prefer the jobs offered to their current jobs, for example, at the status quo level of salary, providing even a single incentive such as good housing or preferential admission to in-service training was preferred by over $60 \%$ of respondents to their current situation, b) packages combining incentives are generally preferred over singleton incentives. For example, the package combining adequate and functional health facility infrastructure, reassignment to an urban area after three years, good housing and preferential admission for in-service training is preferred to the status quo by over $95 \%$ of respondents. On the other hand, keeping the salary level constant, no single incentive is preferred by more than $85 \%$ of respondents.

However, this is not always the case, as is seen from Table 11, where for every level of salary, medical doctors prefer a job package that ensures adequate and functional health facility infrastructure over one that provides both good housing and preferential admission for in-service training after working for 4 years in a rural area, and c) for any incentive, the proportion of

Table 8. WTP estimates for job attributes, medical and nursing students

\begin{tabular}{lccc}
\hline \multirow{2}{*}{ Attribute rank } & \multicolumn{2}{c}{ Medical students } & \multicolumn{1}{c}{ Nursing students } \\
\cline { 2 - 4 } & Attribute & FCFA & Attribute \\
\hline 1 & Health facility Infrastructure & 86,529 & Health facility Infrastructure \\
3 & Job assignment to an urban area & 58,118 & Job assignment to an urban area \\
4 & Lodging & 41,529 & Career development \\
5 & Career development & 25,647 & Lodging \\
\hline
\end{tabular}

WTP= Willingness-to-Pay; FCFA= Franc CFA, the local currency used in Cameroon (500 FCFA= 1 US dollar) 
Table 9. WTP estimates for job attributes, health workers

\begin{tabular}{|c|c|c|c|c|c|c|}
\hline \multirow{2}{*}{$\begin{array}{l}\text { Attribute } \\
\text { rank }\end{array}$} & \multicolumn{2}{|l|}{ Medical doctors } & \multicolumn{2}{|l|}{ State-registered nurses } & \multicolumn{2}{|l|}{ Nurse aides } \\
\hline & Attribute & FCFA & Attribute & FCFA & Attribute & FCFA \\
\hline 1 & Health Facility Infrastructure & 97,000 & Health Facility Infrastructure & 97,846 & Health Facility Infrastructure & 46,480 \\
\hline 2 & Job Assignment to an urban area & 66,462 & Lodging & 40,846 & Career Development & 27,080 \\
\hline 3 & Lodging & 56,231 & Career Development & 38,385 & Lodging & 18,120 \\
\hline 4 & Career Development & 54,923 & Job Assignment to an urban area & 27,308 & $\begin{array}{l}\text { Accessibility and Connectivity of } \\
\text { workplace to the city }\end{array}$ & 10.560 \\
\hline 5 & Accessibility and Connectivity & 37,385 & Accessibility and Connectivity & 21,615 & Job Assignment to an urban area & 3,520 \\
\hline
\end{tabular}

WTP= Willingness-to-Pay; FCFA= Franc CFA, the local currency used in Cameroon (500 FCFA= 1 US dollar)

respondents who prefer a given job to the status quo increases with an increase in salary.

\section{Discussion}

The majority of DCEs examine job preferences of specific cadres of health workers such as nurses (21), nursing students (22), medical students (20) or medical students and doctors (7). Our study looks at job preferences of a variety of cadres represented in the national health system. In particular, in this study we examined the preferences of nurse aides who are seen as the backbone of primary care service delivery in remote and rural areas of the Cameroonian health system. More importantly, this study analyzed health workers' preferences for jobs containing attributes that are currently being discussed as potential policy mechanisms for rural and remote health worker retention by the MoPH. While the sample included cannot be guaranteed to be representative of the general health worker population in the three regions included in the study, and in spite of some limitations to directly inferring WTP estimates from parameter estimates as discussed by Lancsar et al. (30). The results of this study will provide new evidence about the kinds of policies that are likely to be most effective in attracting and retaining health workers in rural Cameroon, effectively linking research to practice and policy. Below

Table 10. Predicted preference impact (percentage) of retention strategy packages for medical students

\begin{tabular}{|c|c|c|c|c|}
\hline \multirow{2}{*}{ Potential retention strategy } & \multicolumn{4}{|c|}{ Salary increase } \\
\hline & $+0 \%$ & $+25 \%$ & $+50 \%$ & $+75 \%$ \\
\hline \multicolumn{5}{|l|}{ Package A } \\
\hline \multicolumn{5}{|l|}{ Ensure adequate and functional health facility infrastructure } \\
\hline \multicolumn{5}{|l|}{ Reassignment to urban area after 3 years in rural post } \\
\hline Provide good housing & $97.34 \%$ & $98.64 \%$ & $99.30 \%$ & $99.65 \%$ \\
\hline \multicolumn{5}{|l|}{ Preferential admission for in-service training after 4 years rural service } \\
\hline \multicolumn{5}{|l|}{ Package B } \\
\hline \multicolumn{5}{|l|}{ Ensure adequate and functional health facility infrastructure } \\
\hline Reassignment to urban area after 3 years in rural post & $95.94 \%$ & $97.91 \%$ & $98.93 \%$ & $99.46 \%$ \\
\hline \multicolumn{5}{|l|}{ Provide good housing } \\
\hline \multicolumn{5}{|l|}{ Package C } \\
\hline \multicolumn{5}{|l|}{ Ensure adequate and functional health facility infrastructure } \\
\hline Provide good housing & $93.21 \%$ & $96.43 \%$ & $98.24 \%$ & $99.07 \%$ \\
\hline \multicolumn{5}{|l|}{ Preferential admission for in-service training after 4 years rural service } \\
\hline Ensure adequate and functional health facility infrastructure & & $9585 \%$ & & $9892 \%$ \\
\hline Reassignment to urban area after 3 years in rural post & $92.12 \%$ & $95.85 \%$ & $9 / .85 \%$ & $98.92 \%$ \\
\hline \multicolumn{5}{|l|}{ Package $\mathrm{E}$} \\
\hline \multicolumn{5}{|l|}{ Ensure adequate and functional health facility infrastructure } \\
\hline Provide good housing & $89.82 \%$ & $94.5 \%$ & $91.1 / \%$ & 98.5\% \\
\hline \multicolumn{5}{|l|}{ Package $\mathbf{F}$} \\
\hline \multicolumn{5}{|l|}{ Reassignment to urban area after 3 years in rural post } \\
\hline Provide good housing & $89.38 \%$ & $94.32 \%$ & $97.04 \%$ & $98.50 \%$ \\
\hline \multicolumn{5}{|l|}{ Preferential admission for in-service training after 4 years rural service } \\
\hline \multicolumn{5}{|l|}{ Package G } \\
\hline \multicolumn{5}{|l|}{ Ensure adequate and functional health facility infrastructure } \\
\hline Preferential admission for in-service training after 4 years rural service & $81.01 \%$ & Y5.00\% & $90.35 \%$ & $98.14 \%$ \\
\hline \multicolumn{5}{|l|}{ Package H } \\
\hline Provide good housing & & & & \\
\hline Preferential admission for in-service training after 4 years rural service & /5.80\% & $86.08 \%$ & $92.43 \%$ & $96.01 \%$ \\
\hline \multicolumn{5}{|l|}{ Package J } \\
\hline Provide good housing & $66.95 \%$ & $79.97 \%$ & $88.76 \%$ & $94.06 \%$ \\
\hline \multicolumn{5}{|l|}{ Package $\mathrm{K}$} \\
\hline Preferential admission for in-service training after 4 years rural service & $60.73 \%$ & $75.32 \%$ & $85.77 \%$ & $92.36 \%$ \\
\hline
\end{tabular}


Table 11. Predicted preference impact (percentage) of retention strategy packages for medical doctors

\begin{tabular}{|c|c|c|c|c|}
\hline \multirow{2}{*}{ Potential retention strategy } & \multicolumn{4}{|c|}{ Salary increase } \\
\hline & $+0 \%$ & $+25 \%$ & $+50 \%$ & $+75 \%$ \\
\hline \multicolumn{5}{|l|}{ Package A } \\
\hline \multicolumn{5}{|l|}{ Ensure adequate and functional health facility infrastructure } \\
\hline \multicolumn{5}{|l|}{ Reassignment to urban area after 3 years in rural post } \\
\hline Provide good housing & $91.30 \%$ & $98.40 \%$ & $99.00 \%$ & $99.40 \%$ \\
\hline \multicolumn{5}{|l|}{ Preferential admission for in-service training after 4 years rural service } \\
\hline \multicolumn{5}{|l|}{ Package B } \\
\hline \multicolumn{5}{|l|}{ Ensure adequate and functional health facility infrastructure } \\
\hline Reassignment to urban area after 3 years in rural post & $94.60 \%$ & $96.70 \%$ & $98.00 \%$ & $98.80 \%$ \\
\hline \multicolumn{5}{|l|}{ Provide good housing } \\
\hline \multicolumn{5}{|l|}{ Package C } \\
\hline \multicolumn{5}{|l|}{ Ensure adequate and functional health facility infrastructure } \\
\hline Provide good housing & $93.70 \%$ & $96.20 \%$ & $97.70 \%$ & $98.60 \%$ \\
\hline \multicolumn{5}{|l|}{ Preferential admission for in-service training after 4 years rural service } \\
\hline \multirow{2}{*}{\multicolumn{5}{|c|}{$\begin{array}{l}\text { Ensure adequate and functional health facility infrastructure } \\
\text { Reassignment to urban area after } 3 \text { years in rural post }\end{array}$}} \\
\hline & & & & \\
\hline \multicolumn{5}{|l|}{ Package E } \\
\hline \multicolumn{4}{|l|}{ Ensure adequate and functional health facility infrastructure } & $97.20 \%$ \\
\hline Provide good housing & & & & של \\
\hline \multicolumn{5}{|l|}{ Package F } \\
\hline \multicolumn{5}{|l|}{ Reassignment to urban area after 3 years in rural post } \\
\hline Provide good housing & $90.90 \%$ & $94.40 \%$ & $96.60 \%$ & $97.90 \%$ \\
\hline \multicolumn{5}{|l|}{ Preferential admission for in-service training after 4 years rural service } \\
\hline \multicolumn{5}{|l|}{ Package G } \\
\hline \\
\hline Preferential admission for in-service training after 4 years rural service & $87.80 \%$ & $92.40 \%$ & $95.30 \%$ & $97.20 \%$ \\
\hline \multicolumn{5}{|l|}{ Package $\mathrm{H}$} \\
\hline $\begin{array}{l}\text { Ensure adequate and functional health facility infrastructure } \\
\text { Package I }\end{array}$ & $77.90 \%$ & $85.60 \%$ & $90.90 \%$ & $94.40 \%$ \\
\hline \multicolumn{5}{|l|}{ Provide good housing } \\
\hline Preferential admission for in-service training after 4 years rural service & $80.90 \%$ & $87.70 \%$ & $92.30 \%$ & $95.30 \%$ \\
\hline \multicolumn{5}{|l|}{ Package J } \\
\hline Provide good housing & $67.50 \%$ & $77.70 \%$ & $85.50 \%$ & $90.90 \%$ \\
\hline \multicolumn{5}{|l|}{ Package K } \\
\hline Preferential admission for in-service training after 4 years rural service & $67.10 \%$ & $77.50 \%$ & $85.20 \%$ & $90.80 \%$ \\
\hline
\end{tabular}

we discuss the results from this study, grouped by attributes included in the DCE choice sets.

\section{Connectivity to urban areas}

Results from this study show that accessibility and connectivity of the health facility to an urban area only has a limited effect on determining job selection. This is an encouraging finding for two reasons. First, there is little that the MoPH can really do to address this contextual factor. Second, it shows that respondents consider other attributes when making their job selection and will not pick a job solely on the basis of its 'better' location. In addition, contrary to findings from similar contexts (9), those brought up in rural areas (who would be presumed to be more used to living in areas with poor connectivity) did not show significantly different preferences from those brought up in urban areas. It is quite likely that educated rural youth (who would tend to be the most ambitious individuals in their communities) would not want to return to rural areas after life in the city. Further qualitative research is needed to explain this result, which diverges from findings in other contexts.

\section{Health facility infrastructure}

We found that health workers greatly value adequate health facility infrastructure. During the preliminary qualitative interviews, respondents often noted that the lack of equipment, supplies and drugs, was a key factor in their determination to avoid posts in remote areas. Our results consistently show that good health facility infrastructure is an important determinant of job choice, and is the job attribute that all cadres value most based on the WTP estimates. This is particularly true for medical students, who are often disappointed by the gap between what they have been trained to do, often based in a tertiary hospital environment, and the availability of drugs and equipment in rural health facilities where they are expected to work upon completing their studies. These results are consistent with those from other DCEs in Sub-Saharan Africa $(22,23)$.

\section{Financial incentives}

We found that all groups of respondents were responsive to higher salaries in the form of a rural retention bonus of $50 \%-$ $75 \%$ of their base salary. However, it is important to note that, in common with Kruk et al. (22) and Blaauw et al. (11), it was identified that salary incentives need to be of substantial value to attract health workers to remote areas.

\section{Quota for continued specialty training}

Findings from this study suggest that the promise of quotas for obtaining specialist training in Cameroon may have only a limited effect on improving rural retention. This is both surprising, given results from DCEs in other settings such as 
Tanzania (20), India (6), and Vietnam (7), and unfortunate, as offering specialist training is an intervention that is relatively easily amenable to policy action by the MoPH. There may be a number of reasons for this; however, an important one that emerged during qualitative interviews was a lack of belief among respondents that the quota would be implemented fairly. This highlights the need to build up a perception of transparent functioning of the public health system in terms of both medical education and job postings. This study also highlights the importance of conducting DCEs that provide policy-makers with locally relevant information.

\section{Housing for health professionals}

Lack of appropriate housing is often cited as an impediment to ensuring an equitable distribution of the health workforce. While the housing attribute in this study was found to be significant, its effect on job selection remained limited. This result suggests that the provision of improved housing can, at best, be part of a package of incentives to attract health workers to rural areas.

\section{Guaranteed transfer to urban areas}

Both students and health workers were more likely to select a job that offered an automatic transfer to an urban area after fixed length of rural service. Among health workers, it was found that medical doctors were most likely to select a job based on this attribute. This is not surprising given their training at teaching level hospitals and limited exposure to the primary healthcare system. There are certain issues that would need to be addressed before such a policy can be introduced. First, it would be necessary to ensure that there are enough health workers to allow for a rotation system to be implemented without rupture. Subsequent analysis on health worker production rates would need to be conducted to assess the feasibility of this policy. Second, the impact of frequent rotation of clinical staff given the administrative bottlenecks that make human resource management inefficient would need to be addressed systemically. The length of rural service after which transfer is guaranteed to an urban area would need to vary, with quicker transfers for serving at the most remote posts. Else there is the risk of marginally-rural posts becoming highly coveted by health workers, leading to new opportunities for corruption in appointments by health administrators. Piloting this strategy in a particular district or region would allow for assessment of its viability. The finding that those brought up in rural areas were particularly keen on an automatic transfer to an urban area after rural service, turns on its head the received wisdom that holds that preferential training to students from rural areas will greatly mitigate rural health worker shortages, due to these students being more amenable to staying in the rural area where they grew up.

\section{Policy implications and conclusions}

In order to respond to the severe geographic imbalances in health outcomes in Cameroon and improve coverage of essential health services, the national health workforce must be distributed in a manner that responds to populations' health needs. While DCEs suffer from limitations such as making providers choose between two hypothetical options and reflecting stated preferences as opposed to actual behavior (23), this study contributes significantly to the building a policy dialogue based on evidence, which remains a challenge in Cameroon where there remains a significant gap in health systems research, particularly for human resources for health. Based on the findings of this study, health workforce retention policies should include a combination of both monetary and non-financial incentives. While introducing a system of substantial monetary bonuses for rural service (potentially in the form of percentage of base salary top-ups as presented in this study) may strengthen retention efforts, the package would be incomplete without ensuring the provision and maintenance of supplies and equipment for the delivery of a clearly defined package of basic services. Over $90 \%$ of doctors and medical students were found to prefer a package comprising a substantial rural retention bonus (of $50 \%$ or more of base salary) with better facilities and equipment (Tables 10 and 11) over their current job. Prior designing a retention strategy package, it would be essential to assess these options and their financial implications within the current budgetary landscape for health financing in Cameroon. Implementation of this policy may be more effective if health facilities were first classified according to varying levels of remoteness. A more nuanced classification would in turn provide greater compensation to those serving in more remote or difficult areas. This in turn may reduce health worker efforts to compete to work in nominally 'rural' areas within commuting distance of towns and cities, something that will undermine the ability of this incentive to effectively address health worker shortages where they are most acute. Beginning with these two measures could provide the foundation of developing a package of interventions to attract health workers to serve in remote areas of Cameroon, an essential step in the country's march towards universal health coverage.

While the primary objective of this study was to identify factors that would influence health workers' decisions to accept and stay in rural and remote areas, the applicability of the findings require a fundamental change in human resources for health management, potentially including the introduction of job vacancy announcements with clear job descriptions for each post. The DCE methodology assumes that clear job descriptions are available and candidates can make informed trade-offs. Yet in most Sub-Saharan African countries, management of the public sector health workforce is highly centralized, with health workers rarely given the option to express their preferences for job postings and usually having very little information about the location they will be posted. These real-life information gaps can contribute negatively on attraction and retention outcomes in several ways. First, health workers who are stationed to an unknown location may develop even before their arrival, a strategy for their reappointment in a place they know better. Second, job sites with attractive conditions could be rejected due to the lack of publicity of their characteristics and lack of information among candidate health workers. Thus, in addition to the abovementioned factors identified by this study as being influential on health worker employment choices, creating a transparent job market with clear job descriptions may also contribute to improving rural retention outcomes.

\section{Acknowledgements}

This work was supported by the World Bank through a trust fund for conducting analytical work on human resources for 
health in the Africa Region. Also, the findings, interpretations and conclusions expressed in the paper are entirely those of the authors, and do not represent the views of the World Bank, its Executive Directors, or the countries they represent. We wish to thank our partners in the $\mathrm{MoPH}$ in Cameroon for helping develop the study methodology and tools, and facilitating data collection. In addition, we would like to thank the interviewers for their dedication in the field during field work.

\section{Ethical issues}

The World Bank received approval for the Cameroon Ministry of Public Health (MoPH) ethical committee in April 2012. All respondents were informed of the research objectives and were asked to take part in the study. Those who agreed were asked to sign a consent form.

Competing interests

The authors declare that they have no competing interests.

\section{Authors' contributions}

PJR and ZS were the principal investigators and led the study design, data analysis and wrote the paper. ORZ, SD, and CK contributed significantly to management of the study throughout the data collection process. SK and GS made substantial contributions to the study design and development of the research question. All authors read and approved the final manuscript.

\section{Authors' affiliations}

${ }^{1}$ The World Bank, Cameroon Country Office, Yaoundé, Cameroon. ${ }^{2}$ World Health Organization, Geneva, Switzerland. 'Ministry of Public Health, Yaoundé, Cameroon. ${ }^{4}$ Institute for Survey and Statistical Analysis, Yaoundé, Cameroon.

\section{References}

1. Travis P, Bennett S, Haines A, Pang T, Bhutta Z, Hyder A, et al. Overcoming health-systems constraints to achieve the Millennium Development Goals. Lancet 2004; 364: 900-6.

2. Miller C, Holly L. Health workers and universal health coverage. Lancet 2012; 380: 1643. doi: 10.1016/S0140-6736(12)61939-4

3. Jimba M, Cometto G, Yamamoto T, Shiao L, Huicho L, Sheikh M. Health workforce: the critical pathway to universal health coverage. In: World Health Organization, editor. First Global Symposium on Health Systems Research. Montreux, Switzerland: WHO; 2010.

4. Anand S, Bärnighausen T. Human resources and health outcomes: cross-country econometric study. Lancet 2004; 364 : 1603-9.

5. Anand S, Bärnighausen T. Health workers and vaccination coverage in developing countries: an econometric analysis. Lancet 2007; 369: 1277-85. doi: 10.1016/S0140-6736(07)605996

6. Rao K, Shroff Z, Ramani S, Khandpur N, Murthy S, Hazarika I, et al. How to Attract Health Workers to Rural Areas? Findings from A Discrete Choice Experiment From India. Washington, DC: The World Bank; 2012.

7. Vujicic M, Alfano M, Shengelia B, Witter S. Attracting Doctors and Medical Students to Rural Vietnam: Insights from a Discrete Choice Experiment. Washington, DC: The World Bank; 2010.

8. Bärnighausen $T$, Bloom DE. Financial incentives for return of service in underserved areas: a systematic review. BMC Health Serv Res 2009; 9: 86. doi: 10.1186/1472-6963-9-86

9. Lehmann U, Dieleman M, Martineau T. Staffing remote rural areas in middle- and low-income countries: A literature review of attraction and retention. BMC Health Serv Res 2008; 8: 19. doi: 10.1186/1472-6963-8-19

10. Franco L, Bennett S, Kanfer R. Health sector reform and public health worker motivation: a conceptual framework. Soc Sci Med 2002; 54: 1255-66.

11. Blaauw D, Erasmus E, Pagaiya N, Tangcharoensathein V, Mullei
$\mathrm{K}$, Mudhune $\mathrm{S}$, et al. Policy interventions that attract nurses to rural areas: a multicountry discrete choice experiment. Bull World Health Organ 2010; 88: 350-6.

12. Mathauer I, Imhoff I. Health worker motivation in Africa: the role of non-financial incentives and human resource management tools. Hum Resour Health 2006; 4: 24.

13. Ministry of Public Health (MoPH). Cameroon Health Workforce Census, 2011. Cameroon: MoPH; 2012.

14. The World Bank. Policy Brief: Improving the Governance of the Health system in Cameroon. Yaounde: The World Bank; 2013.

15. Demographic and Health Survey (DHS). Cameroon Demographic and Health Survey-MICS 2012. Macro International, Inc.; 2012.

16. Demographic and Health Survey (DHS). Cameroon Demographic and Health Survey 2004. Macro International, Inc.; 2004.

17. Mba R, Messi F, Ongolo-Zogo P. Retaining Human Resources for Health in Remote Rural Areas in Cameroon. Policy Brief. Yaoundé: Centre for Development of Best Practices in Health; 2011.

18. Lancsar E, Louviere J. Conducting discrete choice experiments to inform healthcare decision making: a user's guide. Pharmacoeconomics 2008; 26: 661-77.

19. Mangham LJ, Hanson K, McPake B. How to do (or not to do) ... Designing a discrete choice experiment for application in a low-income country. Health Policy Plan 2009; 24: 151-8. doi: 10.1093/heapol/czn047

20. Kolstad J. How to make rural jobs more attractive to health workers. Findings from a discrete choice experiment in Tanzania. Health Econ 2011; 20: 196-211. doi: 10.1002/hec.1581

21. Mangham LJ, Hanson K. Employment preferences of public sector nurses in Malawi: results from a discrete choice experiment. Trop Med Int Health 2008; 13: 1433-41. doi: 10.1111/j.1365-3156.2008.02167.x

22. Kruk ME, Johnson JC, Gyakobo M, Agyei-Baffour P, Asabir K, Kotha SR, et al. Rural practice preferences among medical students in Ghana: a discrete choice experiment. Bull World Health Organ 2010; 88: 333-41. doi: 10.2471/BLT.09.072892

23. Rockers PC, Jaskiewicz W, Wurts L, Kruk ME, Mgomella GS, Ntalazi F, et al. Preferences for working in rural clinics among trainee health professionals in Uganda: a discrete choice experiment. BMC Health Serv Res 2012; 12: 212. doi: 10.1186/1472-6963-12-212

24. Rockers PC, Jaskiewicz W, Kruk ME, Phathammavong O, Vangkonevilay $\mathrm{P}$, Paphassarang $\mathrm{C}$, et al. Differences in preferences for rural job postings between nursing students and practicing nurses: evidence from a discrete choice experiment in Lao People's Democratic Republic. Hum Resour Health 2013; 11: 22. doi: 10.1186/1478-4491-11-22

25. Mandeville KL, Lagarde M, Hanson $\mathrm{K}$. The use of discrete choice experiments to inform health workforce policy: a systematic review. BMC Health Serv Res 2014; 14: 367. doi: 10.1186/14726963-14-367

26. Araújo E, Maeda A. How to Recruit and Retain Health Workers in Rural and Remote Areas in Developing Countries: A Guidance Note. Washington, DC: The World Bank; 2013.

27. Choice Metrics. Ngene Software. 2012 [cited 2012 June 10]. Available from: http://www.choice-metrics.com

28. Street DJ, Burgess L, Louviere JJ. Quick and easy choice sets: constructing optimal and nearly optimal stated choice experiments. International Journal of Research in Marketing 2005; 22: 459-470.

29. Jaskiewicz W, Deussom R, Wurts L, Mgomella G. Rapid Retention Survey Toolkit: Designing Evidence-Based Incentives for Health Workers. Washington, DC: CapacityPlus; 2012.

30. Lancsar E, Louviere J, Flynn T. Several methods to investigate relative attribute impact in stated preference experiments. Soc Sci Med 2007; 64: 1738-53. 